\title{
Diagnosis of pulmonary hypertension from radiographic estimates of pulmonary arterial size
}

\author{
ANDREW BUSH, HUON GRAY, D M DENISON \\ From the Departments of Clinical Physiology and Cardiology, Brompton Hospital, London
}

\begin{abstract}
The reported accuracy of radiographic measurements in predicting pulmonary hypertension is very variable. Measurements of right and left descending pulmonary artery diameter have been reported to provide a correct diagnosis in as many as $98 \%$ of patients. A study was carried out to determine the predictive value of measurements made from the chest radiographs of 50 normal subjects and of 27 patients undergoing right heart catheterisation for cardiac or pulmonary vascular disease, taking account of radiographic magnification. After such corrections a right descending pulmonary artery diameter over $16.7 \mathrm{~mm}$ or a left descending pulmonary artery diameter of over $16.9 \mathrm{~mm}$ distinguished 12 of 23 pulmonary hypertensive subjects, with no false positive results. The diameter was then arbitrarily squared (any differences between patients and control subjects being exaggerated) and the product was divided by either predicted or actual lung volume in an attempt to correct for body size. The new index distinguished 19 of 23 patients with pulmonary hypertension, with one false positive, when the divisor was actual lung volume; when predicted lung volume was used 18 of 23 patients were distinguished, again with one false positive result.
\end{abstract}

Many previous workers have attempted to predict pulmonary haemodynamics from chest radiographs, ${ }^{1-6}$ but this has proved difficult. Recently, measurement of the diameter of the descending pulmonary artery was reported to be a good method of diagnosing pulmonary hypertension complicating chronic obstructive pulmonary disease. ${ }^{78}$ The diagnostic criteria and results are, however, different in the two papers cited. We therefore report our results with similar measurements to which we have made corrections for magnification and body size.

\section{Methods}

The normal controls were 50 people who underwent chest radiography as part of routine medical examinations. There were 41 men and nine women, mean age 27, range 19-39 years. None had any evidence of appreciable cardiopulmonary disease from their history and physical examination, and all had normal chest radiographs. Twenty individuals had radiographs at a tube film distance of 1.8 metres $(6 \mathrm{ft})$ Address for reprint requests: Dr Andrew Bush, Department of
Clinical Physiology, Brompton Hospital, London SW3 6HP.

Accepted 3 November 1987 (kindly provided by Dr D Stanescu) and the remainder had 3 metre $(10 \mathrm{ft})$ radiographs. None underwent cardiac catheterisation.

The patients were 27 individuals (seven men) undergoing diagnostic cardiac catheterisation for clinical purposes. The age, sex, diagnosis, and mean pulmonary artery pressure of each are shown in table 1 . Chest radiographs were performed at a tube film distance of $3 \mathrm{~m}$. Pulmonary artery pressures were recorded relative to the mid axillary line with fluid filled catheters in the supine posture at functional residual capacity. An electrically low pass filtered mean was taken, and recorded by an independent observer. All radiographic measurements were made without knowledge of the pulmonary artery pressures.

Identical radiographic techniques were used for the normal controls and the patients. Subjects were instructed to breathe in as far as possible, and radiographs were exposed only after they had signalled that full inspiration had been reached. They were then asked to turn through 90 degrees, and a left lateral film was taken; again subjects were allowed to reach total lung capacity before exposure, without alteration of the height of the $x$ ray tube and film plate.

From the radiographs the following measurements were made by a single observer. The posteroanterior and lateral diameters of the thorax were measured so that overall magnification could be calculated..$^{90}$ The 
Table 1 Details of the 27 patients catheterised

\begin{tabular}{|c|c|c|c|}
\hline $\begin{array}{l}\text { Age } \\
(y)\end{array}$ & Sex & Diagnosis & $\begin{array}{l}\text { Mean PAP } \\
(m m H g)\end{array}$ \\
\hline $\begin{array}{c}36 \\
47 \\
67 \\
56 \\
57 \\
25 \\
67 \\
54 \\
50 \\
59 \\
56 \\
55 \\
77 \\
65 \\
59 \\
68 \\
52 \\
78 \\
51 \\
57 \\
52 \\
71 \\
59 \\
20 \\
65 \\
54 \\
74 \\
57 \\
\text { Mange } 20-78\end{array}$ & $\begin{array}{l}F \\
F \\
M \\
\text { F } \\
M \\
F \\
M \\
F \\
F \\
M \\
M \\
F \\
F \\
F \\
F \\
F \\
F \\
M \\
F \\
F \\
F \\
F \\
F \\
F \\
F \\
F\end{array}$ & $\begin{array}{l}\text { Normal } \\
\text { PS } \\
\text { MR/IHD } \\
\text { IHD } \\
\text { MS/AR } \\
\text { COARC } \\
\text { MR/MS } \\
\text { MR } \\
\text { MR/AR } \\
\text { ASD/IHD } \\
\text { MR } \\
\text { MS/MR } \\
\text { MS } \\
\text { MR/MS/IHD } \\
\text { MS/AR } \\
\text { MR/MS/IHD } \\
\text { MR/MS/IHD } \\
\text { MS/AR/AS } \\
\text { IHD } \\
\text { MS } \\
\text { MR/MS } \\
\text { MR/MS/AS } \\
\text { PPH } \\
\text { ASD } \\
\text { MR/IHD } \\
\text { AS/CM } \\
\text { PE }\end{array}$ & $\begin{array}{l}12 \\
15 \\
15 \\
15 \\
18 \\
19 \\
19 \\
20 \\
22 \\
23 \\
24 \\
25 \\
30 \\
31 \\
35 \\
37 \\
39 \\
40 \\
40 \\
40 \\
42 \\
43 \\
45 \\
47 \\
54 \\
68 \\
70 \\
33 \\
12-70\end{array}$ \\
\hline
\end{tabular}

MR-mitral regurgitation; MS-mitral stenosis; AR-aortic regurgitation; AS-aortic stenosis; IHD-ischaemic heart disease; PSpulmonary stenosis; COARC - coarctation; ASD-atrial septal defect; PPH-primary pulmonary hypertension; $\mathrm{CM}-$ cardiomyopathy; PE - multiple pulmonary emboli.

maximum diameters of the right and left descending pulmonary arteries (RDPA, LDPA) were taken as the mean of three measurements, Vernier calipers being used. The RDPA is the largest artery leaving the right hilum, and its width was measured at its widest diameter before the bifurcation into middle and lower lobe arteries. The LDPA curves posteriorly and inferiorly across the aortic window on the lateral projection. The anterior margin of this artery was measured from the posterior wall of the left upper lobe bronchus viewed end on, and the posterior margin was selected at its widest diameter. ${ }^{7}$ The diameters of the arteries were corrected for magnification."

Other measurements made were the transhilar width, the posteroanterior and lateral internal transverse thoracic diameters, and the mean heights and widths of the 9th, 10th, and 11 th thoracic vertebral bodies. The transhilar width was obtained by summing the horizontal distances from the midline to the first radiologically visualised upper lobe arterial division on each side. ${ }^{12}$ The transverse diameters of the thorax are the maximal distances from the midline to the inner aspects of the ribs on both sides in the posteroanterior film, and from the back of the sternum to the posterior aspect of the lung on the lateral film. The 9th-11th thoracic vertebral bodies were chosen because they were most easily and consistently identifiable on the lateral radiographs. The 12th thoracic vertebra was often obscured by the diaphragm and the margins of the upper thoracic vertebrae were often difficult to identify, and the bodies themselves were sometimes porotic and collapsed in older subjects. Finally, the chest radiographs were digitised, and total lung capacity was measured as previously described. ${ }^{910}$ Predicted total lung capacity was calculated from the regression equations of Black et al. ${ }^{13}$

All patients and subjects gave informed consent. The procedures were covered by approval from the Brompton Hospital ethics committee.

\section{Results}

In the normal subjects, mean RDPA was 14 (range $11 \cdot 2-17 \cdot 4) \mathrm{mm}$. The corresponding figures for LDPA were $13.4(10.4-18.0) \mathrm{mm}$. When corrected for magnification, mean RDPA was 13.3 (range 10.716.7) $\mathrm{mm}$ and mean LDPA 12.7 (range 9.9-16.9) $\mathrm{mm}$. There was a trend for both measurements to decrease with increasing age, but this did not reach statistical significance. Men had significantly larger arterial diameters than women (difference in mean RDPA between male and female subjects $2 \mathrm{~mm}, \mathrm{p}<0.001$, and for LDPA $1.4 \mathrm{~mm}, \mathrm{p}<0.02$, unpaired $t$ test).

Four patients had a normal mean pulmonary artery pressure (PAP) and 23 had pulmonary hypertension (PAP $>15 \mathrm{~mm} \mathrm{Hg}^{14}$ ). The RDPA diameter, corrected for magnification, was outside the normal range in

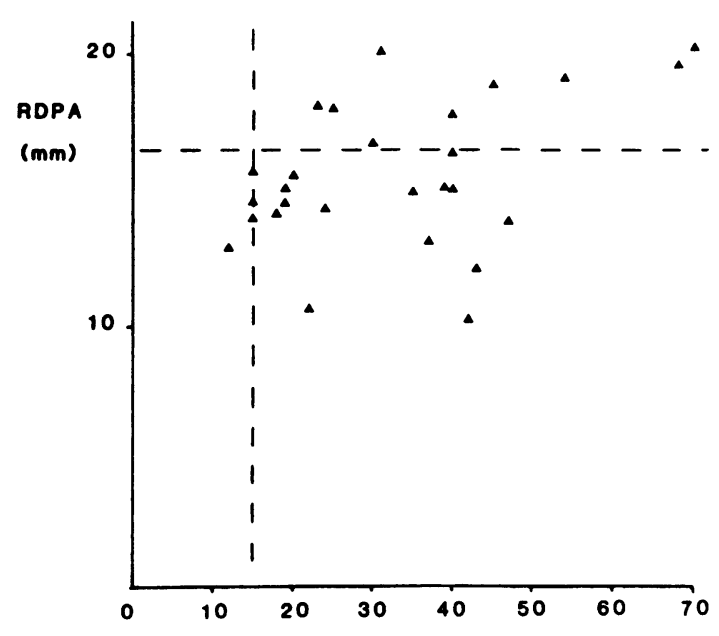

Pulmonary artery pressure $(\mathrm{mm} \mathrm{Hg})$

Fig 1 Right descending pulmonary artery diameter (RDPA) corrected for magnification and plotted against mean pulmonary artery pressure. The dotted lines mark the upper limits of the normal ranges. 
Table 2 Correction of pulmonary artery diameters by lung size in normal subjects

\begin{tabular}{llll}
\hline & Mean & $S D$ & Range \\
\hline IRP & 0.265 & 0.046 & $0 \cdot 183-0.402$ \\
ILP & 0.247 & 0.062 & $0.157-0.425$ \\
IRM & 0.268 & 0.053 & $0 \cdot 176-0.406$ \\
ILM & 0.249 & 0.066 & $0.148-0.469$ \\
\hline
\end{tabular}

RDPA-right descending pulmonary artery; LDPA-left descending pulmonary artery; IRP-RDPA/predicted TLC; ILPLDPA/predicted TLC; IRM-RDPA/measured TLC; ILMLDPA/measured TLC.

nine of 23 patients with pulmonary hypertension (fig 1) and the LDPA diameter in six, and one or both diameters were abnormal in 11 of the 23 patients. There were no false positives. The diameters corrected for magnification correlated very weakly with mean pressure $(\mathrm{PAP}=\mathrm{RDPA} \times 23.77-4.57, \mathrm{r}=0.43, \mathrm{p}$ $<0.05 ;$ PAP $=$ LDPA $\times 22.05-0.20, r=0.42, \mathrm{p}<$ $0.05)$. The upper limit of normal for the hilar thoracic index $^{8}$ was $34.9 \mathrm{~mm}$ in this series. The index was abnormal in only 12 of the 23 patients with pulmonary hypertension. If the criteria of Chetty et al are used (index $>36 \mathrm{~mm}$ ), the figure falls to 7 out of 23 .

The size of the arteries was scaled for body size by dividing by lung width and by mean vertebral body height and width. The hilar width was also corrected for magnification and by division by vertebral body height and width. None of these scaling factors improved accuracy significantly, and the results will not be discussed further.

Artery size was also corrected for predicted and radiologically measured total lung capacity. The flow through an artery is likely to be partly a function of its area. Four indices were developed from the general equation index $=[($ diameter squared $) / L]$, where $L$ is predicted or measured total lung capacity (litres) and diameter is true RDPA or LDPA diameter, corrected for magnification. The indices are abbreviated to IRM (RDPA/measured total lung capacity), ILM (LDPA/ measured total lung capacity), IRP (RDPA/predicted total lung capacity), and ILP (LDPA/predicted total lung capacity). The results for normal subjects are given in table 2 . None of these indices correlated significantly with age, and there were no significant differences between the sexes (unpaired $t$ test).

The index IRM was outside the normal range in 17 of the 23 patients with pulmonary hypertension, with one false positive (fig 2); ILM was abnormal in 14 out of 23, with no false positives. One or both indices were abnormal in 19 out of 23 . Both these indices correlated with mean pulmonary artery pressure: $P A P=I R M \times$ $47.62+7.03, \mathrm{r}=0.63, \mathrm{p}<0.001 ;$ PAP $=$ ILM $\times$ $37.74+13.96, r=0.55, p<0.01$. For the index IRP the figures were $17 / 23$ (one false positive) for the index IRP and 13/23 (no false positives) for ILP. One or both

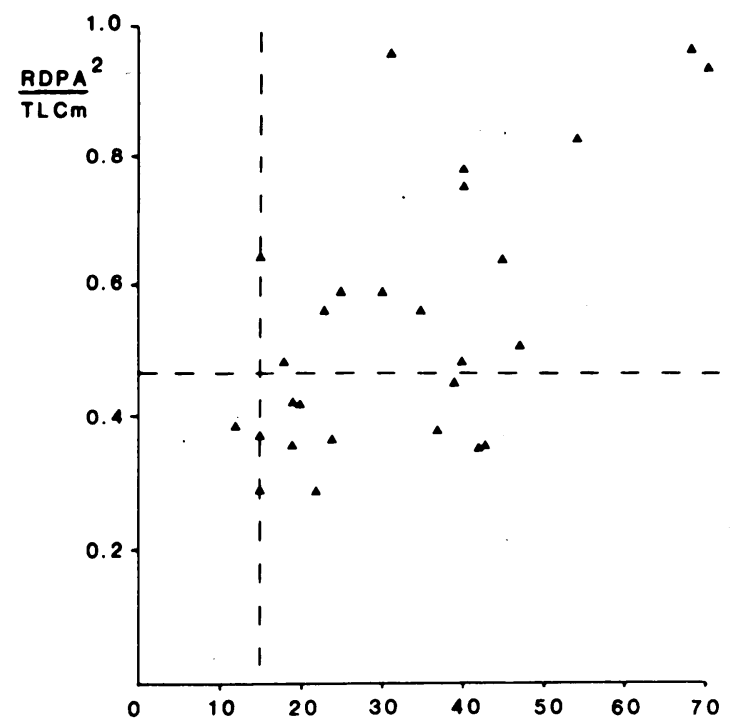

Pulmonary artery pressure $\left(\mathrm{mm} \mathrm{Hg}_{\mathrm{g}}\right)$

Fig 2 Right descending pulmonary artery diameter ( $R D P A$ ) corrected for magnification, squared, and scaled for radiographically measured total lung capacity $\left(R D P A^{2}\right)$

$T L C m$ ) plotted against mean pulmonary artery pressure. The dotted lines mark the upper limits of the normal ranges.

indices were abnormal in 18 of the 23 . Similarly, both these indices correlated with mean pressure: PAP $=$ IRP $\times 49.50+7 \cdot 76, \mathrm{r}=0.61, \mathrm{p}<0.001 ;$ PAP $=$ ILP $\times 39 \cdot 59+14 \cdot 39, \mathrm{r}=0.53, \mathrm{p}<0.01$. The subject with pulmonary stenosis gave a false positive result for both IRM and IRP. Finally, we looked at the results if diameter was cubed or raised to a higher power, but diagnostic accuracy could not be improved.

\section{Discussion}

The measurement of the diameters of the right and left descending pulmonary arteries was not in our hands a sensitive way of detecting pulmonary hypertension. In this series the two diameters were within the normal range in more than half the patients with pulmonary hypertension. One possibility is that our disappointing results were due to the age discrepancy between the normal subjects and the patients. Our normal values for the right descending pulmonary artery are similar to those from the largest series (1085 cases), reported by Chang. ${ }^{\text {s }}$ Chang found a trend for an increasing right descending pulmonary artery diameter with age, but the upper limit of normal was not age related in his subjects. Men had slightly larger arteries than women. The upper limit of the normal range of left descending pulmonary artery diameters reported by Matthay et 
al is $1 \mathrm{~mm}$ greater than ours; radiological technical details are not described in their paper, and may account for the discrepancy. In our study the control subjects were younger than the patients and had a higher proportion of men. The mean control values of artery diameters might therefore be slightly higher than would be appropriate for the patients, but the upper limit of normal is likely to be correct, and is similar to findings in other studies. ${ }^{7815}$

A more likely explanation for the relatively low sensitivity of the measurements is that pressure is not the only determinant of the pulmonary artery size. Another important factor is wall compliance, which varies with age ${ }^{1617}$ and disease. ${ }^{1819}$ The diameter also varies with lung size, ${ }^{15}$ the cardiac cycle, ${ }^{20}$ and radiological magnification. ${ }^{10}$ Even measurements of right and left descending pulmonary artery based on computed tomography have proved disappointing. ${ }^{21}$ Main pulmonary artery diameter may be better, ${ }^{21}$ but this cannot be measured from standard radiographs, and even with computed tomography five out of 16 cases of pulmonary hypertension were not detected. The loose relationship between pressure and artery diameter is the probable reason for the inconsistencies found in published reports. Chetty et al found that 19 of 20 patients with a mean pulmonary artery pressure of more than $20 \mathrm{~mm} \mathrm{Hg}$ had a right descending pulmonary artery diameter greater than $20 \mathrm{~mm}$. In the series of Matthay et al the proportion was 28/61 and in our series $2 / 17$.

To try to improve the detection of increases in pulmonary artery pressure, we scaled the pulmonary artery diameters for size of the subjects. A similar idea has been used many times before (on the basis, for example, of the thoracic width ${ }^{8}$ or vertebral body size $^{22}$ ) but scaling by measured or predicted total lung capacity has not been reported, despite the many regression equations relating total lung capacity to sex and height. As the flow through an artery will be partly a function of its area, diameter squared was arbitrarily scaled to total lung capacity.

On the basis of predicted values of total lung capacity, the right or left index was abnormal in 18 out of 23 cases of pulmonary hypertension, and on the basis of radiographically measured total lung capacity 19 of the 23 cases were successfully detected. A similar improvement in accuracy, based on pulmonary artery size scaled for body surface area, has been reported by others. ${ }^{21}$ We had one false positive result, from a woman with pulmonary stenosis at the time of study; in this patient the enlarged artery might have represented post-stenotic dilatation, one of many causes of large pulmonary arteries with normal pressure. ${ }^{23-25}$

In this group of patients predicted and radiologically measured total lung capacity were about equally useful for scaling of artery size. This is unlikely to be the case in diseases causing large changes in total lung capacity, such as emphysema. The arguments for using measured total lung capacity are that the information is available from the film without storing extra data and that pulmonary artery diameter increases with inspiration. ${ }^{15}$ Predicted total lung capacity, however, is not affected by the presence of disease. The appropriateness of each can be resolved only by further studies. In the patients measured total lung capacity was significantly greater than predicted (mean difference $329 \mathrm{ml}$, standard deviation of the difference $640 \mathrm{ml} ; \mathrm{p}<0.02$, paired $t$ test), whereas in the normal subjects there was no significant difference.

In conclusion, the right and left descending pulmonary artery diameter squared, corrected for magnification and scaled to either measured or predicted total lung capacity, can be used to make a correct diagnosis $\frac{\mathbb{D}}{0}$ of pulmonary hypertension in more than $75 \%$ of patients with various cardiac diseases. A normal index does not, however, exclude pulmonary hypertension. $\vec{\theta}$ Although there are weak correlations between mean $\infty$ pressure and these indices, the scatter is so wide that the absolute pressure cannot be predicted radiologically. Further studies are needed to determine whether similar accuracy is possible in other diseases, particularly when the disease process might alter the compliance of the arterial wall or obscure the arteries themselves. Further studies are also required to assess whether measured or predicted total lung capacity are more useful to scale the arterial areas.

AB is supported by the British Heart Foundation.

\section{References}

1 Grainger RG. Interstitial pulmonary oedema and its radiological diagnosis. A sign of pulmonary venous and capillary hypertension. $B r J$ Radiol 1958;31: 201-17.

2 Johnson PM, Wood EH, Pasternack BS, Jones MA. Roentgen evaluation of pulmonary arterial pressure in mitral stenosis. Radiology 1961;76:541-7.

3 Lavender JP, Doppman J, Shawdon H, Steiner RE. Pulmonary veins in left ventricular failure and mitral stenosis. Br J Radiol 1962;35:293-302.

4 Chen JTT, Behar VS, Morris JJ, McIntosh HD, Lester RG. Correlation of roentgen findings with haemodynamic data in pure mitral stenosis. $A J R$ 1968;102: 280-92.

5 Forrester JS, Diamond GA, Swan HJC. Correlative classification of clinical and hemodynamic function after acute myocardial infarction. Am $J$ Cardiol 1977;39:137-45

6 Dash H, Lipton MJ, Chatterjee K, Parmley WW. Estimation of pulmonary artery wedge pressure from chest radiograph in patients with chronic congestive car- 
diomyopathy and ischaemic cardiomyopathy. $\mathrm{Br}$ Heart J 1980;44:322-9.

7 Matthay RA, Schwarz MI, Ellis JH, et al. Pulmonary artery hypertension in chronic obstructive pulmonary disease: determination by chest radiography. Invest Radiol 1981;16:95-100.

8 Chetty KG, Brown SE, Light RW. Identification of pulmonary hypertension in chronic obstructive pulmonary disease from routine chest radiographs. $\mathrm{Am}$ Rev Respir Dis 1982;126:338-41.

9 Pierce RJ, Brown DJ, Holmes M, Cumming G, Denison DM. The estimation of lung volume from chest radiographs using shape information. Thorax 1979;34:726-34.

10 Bush A, Denison DM. Use of different magnification factors to calculate radiological lung volumes. Thorax 1986;41:158-9.

11 Bush A. The functional assessment of human pulmonary circulation. MD thesis, University of Cambridge, 1987.

12 Lupi E, Dumont C, Tejada VM, Horwitz S, Galland F. A radiologic index of pulmonary arterial hypertension. Chest 1975;68:28-31.

13 Black LF, Offord K, Hyatt RE. Variability in the maximal expiratory flow volume curve in asymptomatic smokers and in non-smokers. Am Rev Respir Dis 1974;110:282-92.

14 Harris $P$, Heath $D$. The human pulmonary circulation. 2nd ed. Edinburgh: Churchill Livingstone, 1986:84.

15 Chang $\mathrm{CH}$. The normal roentgenographic measurement of the right descending pulmonary artery in 1085 cases. AJR 1962;87:929-35.

16 Harris P, Heath D, Apostolopoulos A. Extensibility of the human pulmonary trunk. Br Heart $J$ 1965;27: $651-9$.

17 Castillo Y, Kruger H, Arias-Stella J, Hurtado A, Harris P, Heath D. Histology, extensibility and chemical composition of pulmonary trunk in persons living at sea level and high altitude in Peru. Br Heart $J$ 1967;29:120-8.

18 Harris P, Heath D, Apostolopoulos A. Extensibility of the pulmonary trunk in heart disease. Br Heart $J$ 1965;27:660-6.

19 Reuben SR, Butler J, Lee G de J. Pulmonary artery compliance in health and disease. Br Heart $J$ 1971;33:147.

20 Patel DJ, Schilder DP, Mallos AJ. Mechanical properties and dimensions of the major pulmonary arteries. J Appl Physiol 1960;15:92-6.

21 Kuriyama K, Gamsu G, Stern RG, Cann CE, Herfkens RJ, Brundage BH. CT-determined pulmonary artery diameters in predicting pulmonary hypertension. Invest Radiol 1984;19:16-22.

22 Aronberg DJ, Glazer HS, Madsen K, Sagel SS. Normal thoracic aortic diameters by computed tomography. J Comput Assist Tomogr 1984;8:247-50.

23 Simon G. Principles of chest X-ray diagnosis. 4th ed. London: Butterworth, 1978:194-6.

24 Raphael MJ, Donaldson RM. In: Sutton D, ed. $A$ textbook of radiology and imaging. 4th ed. London: Churchill Livingstone, 1987:564-84.

25 Hopkins RA, Hammon JW, McHale PA, Smith PK, Anderson RW. Pulmonary vascular impedance analysis of adaptation to chronically elevated blood flow in the awake dog. Circ Res 1979;45:267-74. 